\title{
IPEM Topical Report: an international IPEM survey of MRI use for external beam radiotherapy treatment planning
}

DOI:

10.1088/1361-6560/abe9f7

10.1088/1361-6560/abe9f7

\section{Document Version}

Accepted author manuscript

Link to publication record in Manchester Research Explorer

\section{Citation for published version (APA):}

Speight, R., Tyyger, M., Schmidt, M. A., Liney, G. P., Johnstone, R., Eccles, C. L., Dubec, M., George, B., Henry, A., Herbert, T., Nyholm, T., Mahmood, F., Korhonen, J., Sims, R., Tijssen, R. H. N., Vanhoutte, F., Busoni, S., Lacornerie, T., \& McCallum, H. M. (2021). IPEM Topical Report: an international IPEM survey of MRI use for external beam radiotherapy treatment planning. Physics in Medicine and Biology, 66(7), [075007].

https://doi.org/10.1088/1361-6560/abe9f7, https://doi.org/10.1088/1361-6560/abe9f7

\section{Published in:}

Physics in Medicine and Biology

\section{Citing this paper}

Please note that where the full-text provided on Manchester Research Explorer is the Author Accepted Manuscript or Proof version this may differ from the final Published version. If citing, it is advised that you check and use the publisher's definitive version.

\section{General rights}

Copyright and moral rights for the publications made accessible in the Research Explorer are retained by the authors and/or other copyright owners and it is a condition of accessing publications that users recognise and abide by the legal requirements associated with these rights.

\section{Takedown policy}

If you believe that this document breaches copyright please refer to the University of Manchester's Takedown Procedures [http://man.ac.uk/04Y6Bo] or contact uml.scholarlycommunications@manchester.ac.uk providing relevant details, so we can investigate your claim.

\section{OPEN ACCESS}




\section{IPEM Topical Report: An international IPEM survey of MRI use for external beam radiotherapy treatment planning}

To cite this article before publication: Richard Speight et al 2021 Phys. Med. Biol. in press https://doi.org/10.1088/1361-6560/abe9f7

\section{Manuscript version: Accepted Manuscript}

Accepted Manuscript is "the version of the article accepted for publication including all changes made as a result of the peer review process, and which may also include the addition to the article by IOP Publishing of a header, an article ID, a cover sheet and/or an 'Accepted

Manuscript' watermark, but excluding any other editing, typesetting or other changes made by IOP Publishing and/or its licensors"

This Accepted Manuscript is $\odot 2021$ Institute of Physics and Engineering in Medicine.

During the embargo period (the 12 month period from the publication of the Version of Record of this article), the Accepted Manuscript is fully protected by copyright and cannot be reused or reposted elsewhere.

As the Version of Record of this article is going to be / has been published on a subscription basis, this Accepted Manuscript is available for reuse under a CC BY-NC-ND 3.0 licence after the 12 month embargo period.

After the embargo period, everyone is permitted to use copy and redistribute this article for non-commercial purposes only, provided that they adhere to all the terms of the licence https://creativecommons.org/licences/by-nc-nd/3.0

Although reasonable endeavours have been taken to obtain all necessary permissions from third parties to include their copyrighted content within this article, their full citation and copyright line may not be present in this Accepted Manuscript version. Before using any content from this article, please refer to the Version of Record on IOPscience once published for full citation and copyright details, as permissions will likely be required. All third party content is fully copyright protected, unless specifically stated otherwise in the figure caption in the Version of Record.

View the article online for updates and enhancements. 


\section{IPEM Topical Report: An international IPEM survey of MRI use for external beam radiotherapy treatment planning}

\section{Contact Email \\ Richard.speight@nhs.net}

\section{Author list:}

Richard Speight, Leeds Cancer Centre, Leeds Teaching Hospitals NHS Trust, Leeds, UK Marcus Tyyger, Leeds Cancer Centre, Leeds Teaching Hospițals NHS Trust, Leeds, UK

Maria A. Schmidt, Royal Marsden NHS Foundation Trust and Institute of Cancer Research, London, UK

Gary Liney, Ingham Institute for Applied Medical Research \& Liverpool Cancer Therapy Centre, Liverpool, Sydney, NSW 2170, Australia

Robert Johnstone, Guy's and St. Thomas' NHS Foundation Trust, London, UK

Cynthia L Eccles, The Christie NHS Foundation Trust and the University of Manchester, Manchester, UK

Michael Dubec, The Christie NHS Foundation Trust and the University of Manchester, Manchester, UK

Ben George, University of Oxford and GenesisCare, Oxford, UK

Ann Henry, Leeds Cancer Céntre, Leeds Teaching Hospitals NHS Trust and University of Leeds, Leeds, UK

Trina Herbert, Royal Marsden NHS Foundation Trust, London, UK

Tufve Nyholm, Department of radiation sciences, Umeå University, Sweden 
Faisal Mahmood, Odense University Hospital, Laboratory of Radiation Physics, Odense, Denmark and University of Southern Denmark, Department of clinical Research, Denmark Juha Korhonen, Department of Medical Imaging and Radiation Therapy, Kymenlaakso Central Hospital, Kotka, Finland

Rick Sims, Auckland Radiation Oncology, Epsom, Auckland, New Zealand and Icon Cancer Centres, Cairns, QLD, Australia

Rob HN Tijssen, Department of Radiation Oncology, Catharina Hospital, Eindhoven, the Netherlands

Frederik Vanhoutte, Department of Radiation Oncology, Ghent University Hospital, Belgium Simone Busoni, Department of Health Physics, AOU Careggi (Firenze University Hospital), Firenze, Italy

Thomas Lacornerie, Department of Medical Physics, Centre Oscar Lambret, Lille, France Hazel McCallum, Translational and Clinical Research/nstitute, Newcastle University and Northern Centre for Cancer Care, Newcastle upon Tyne Hospitals NHS Foundation Trust, Newcastle upon Tyne, UK

\section{ORCID iDs}

Richard Speight https://orcid.org/0000-0001-8981-1640

Maria A Schmidt https://orcid.org/0000-0001-8993-5301

Robert I Johnstone https://orcid.org/0000-0003-2711-9469

Cynthia LEccles https://orcid.org/0000-0002-5445-5428

Ann Henry https://orcid.org/0000-0002-5379-6618

Hazel McCallum https://orcid.org/0000-0001-5121-2335 
Michael Dubec https://orcid.org/0000-0001-7758-3310

Marcus Tyyger https://orcid.org/0000-0001-8491-1298

Rob Tijssen https://orcid.org/0000-0003-1355-7150

Faisal Mahmood https://orcid.org/0000-0002-7270-7967

\section{Conflict of interest:}

None

\section{Keywords}

Audit, Survey, MRI, radiotherapy, international 


\begin{abstract}
Introduction/Background:

Despite growing interest in Magnetic Resonance Imaging (MRI), integration in external beam radiotherapy (EBRT) treatment planning uptake varies globally. In order to understand the current international landscape of MRI in EBRT a survey has been performed in 11 countries. This work reports on differences and common themes identified.

Methods:

A multi-disciplinary Institute of Physics and Engineering in Medicine (IPEM) working party modified a survey previously used in the UK to understand current practice using MRI for EBRT treatment planning, investigate how MRI is currently used and managed as well as identify knowledge gaps. It was distributed electronically within 11 countries: Australia, Belgium, Denmark, Finland, France, Italy, the Netherlands, New Zealand, Sweden, the UK and the USA.
\end{abstract}

Results:

The survey response rate within the USA was $<1 \%$ and hence these results omitted from the analysis. In the other 10 countries the survey had a median response rate of $77 \%$ per country.

Direct MRI access, defined as either having a dedicated MRI scanner for radiotherapy (RT) or access to a radiology MRI scanner, varied between countries. France, Italy and the UK reported the lowest direct MRI access rates and all other countries reported direct access in $\geq 82 \%$ of centres. Whilst $\geq 83 \%$ of centres in Denmark and Sweden reported having dedicated $M R I$ scanners for EBRT, all other countries reported $\leq 29 \%$. Anatomical sites receiving MRI for EBRT varied between countries with brain, prostate, head and neck being most common. Commissioning and QA of image registration and MRI scanners varied greatly, as did MRI sequences performed, staffing models and training given to different staff groups. The lack of financial reimbursement for MR was a consistent barrier for MRI implementation for RT 
for all countries and MR access was a reported important barrier for all countries except Sweden and Denmark.

Conclusion:

No country has a comprehensive approach for MR in EBRT adoption and financial barriers are present worldwide. Variations between countries in practice, equipment, staffing models, training, QA and MRI sequences have been identified, and are likely to be due to differences in funding as well as a lack of consensus or guidelines in the literature. Access to dedicated MR for EBRT is limited in all but Sweden and Denmark, but in all countries there are financial challenges with ongoing per patient costs. Despite these challenges, significant interest exists in increasing MR guided EBRT planning over the next 5 years.

\section{Introduction}

The potential benefits of Magnetic Resonance Imaging (MRI) to increase accuracy of tumour and normal tissue delineation to optimise external beam radiotherapy (EBRT) treatment planning has been well documented (Curran et al 1986, Rai et al 2017, Kupelian and Sonke 2014, Raaymakers et al 2009, Pollard et al 2017). Due to these benefits there is a growing impetus in the literature (Erler et al 2018, Glide-hurst et al 2016) and from recommendations that EBRT centres have more access to MRI scanners. For example, in the UK there is a recommendation that for each 2 to 4 million people served by a radiotherapy 
(RT) centre there should be at least 0.7 of a dedicated MR scanner's time available to guide treatment planning (Cancer Research UK 2015). It was recently reported by an internal survey of a single centre with an MRI scanner dedicated for EBRT that 32\% of all patients received an MRI scan as part of their patient pathway (Liney 2018) suggesting that the demand for MRI for EBRT planning can be this high.

There are challenges that must be overcome in order to use MRI in the EBRT treatment planning pathway and understanding these challenges is key to implementing this technology safely. One challenge is that at the time of the survey there was little consensus in the literature or guidance on how to safely implement MRI for EBRT, although this is something that the Institute of Physics and Engineering in Medicine (IPEM) has now published (Speight et al 2021)and the American Association of Medical Physics (AAPM) is aiming to publish on imminently.

IPEM have commissioned a working party to provide guidance on the safe use of MRI for EBRT. In order to understand the current practice of the use of MRI for EBRT treatment planning, the IPEM working party undertook a survey of all UK centres in 2018 (Speight et al 2019). The key findings of this survey in the UK were firstly that although most centres have some MRI access, uptake was low ( $6 \%$ of EBRT patients in England received an MRI scan as part of their treatment). The second key finding in the UK was that the primary barriers to further implementation of MRI for EBRT were a lack of reimbursement for MRI and a lack of MRI access. The final key finding in the UK was that a large variability was reported in implementation of many aspects of MRI for RT, including commissioning and quality assurance of image registration/MRI scanners, as well as staffing models and training. The large reported variability in MRI for RT implementation in the UK was thought to be, in part, due to a lack of guidance or consensus in the literature.

The uptake of MRI for EBRT in other countries has not been documented in the literature as thoroughly as Speight et al. have reported it in the UK. However, it is known that global RT access varies significantly, ranging from having $34 \%$ of the provision required in Africa, 92\% in Europe and $195 \%$ in North America (Zubizarreta et al 2017). In order to further understand the current role of MRI for EBRT, the work presented here is an extension of the survey reported by Speight et al. The specific aims of this new survey were to (1) understand 
the differences in MRI for RT uptake and use between countries, (2) understand current practice of the use of MRI for EBRT treatment planning, (3) investigate how MRI is currently used and managed and (4) identify knowledge gaps in the field. The results of this survey were used to inform guidance, endorsed by IPEM, on the use of MRI for EBRT treatment planning and to ensure the guidance produced was relevant for the RT community. This survey considered the use of MRI for photon EBRT treatment planning only. Proton therapy, gamma radiosurgery, intraoperative RT and brachytherapy were considered specialist treatments and thus beyond the scope of this work. MRI guidance during treatment was also considered beyond the scope of the work presented here, with the exception of asking if centres currently had or are planning for MRI-linac technology.

\section{Method}

The survey used was modified from the UK survey discussed by (Speight et al 2019). The original survey was developed by a nine member, multidisciplinary IPEM working party tasked with producing guidelines on the use of MRI in EBRT treatment planning and it comprised of 10 sections:

1. MRI access

2. Clinical sites in which MRI is used for EBRT treatment planning

3. MRI equipment

4. MRI pulse sequence details

5. MRI to CT registration

6. MRI commissioning and quality assurance (QA)

7. MRI safety

8. Workflow, staffing and training

9. Barriers to implementation of MRI for EBRT planning

10. Future applications of MRI 
In the following 11 countries, local contacts were collaborated with to modify the survey terminology for improved clarity and comprehension in their country. However, the meaning of the questions was held constant so that data could be compared fairly between countries. An example of the survey used in the UK is included in the appendix in (Speight et al 2019).

- Australia (AU)

- Belgium (BE)

- $\quad$ Denmark (DK)

- Finland (FN)

- France (FR)

- Italy (IT)

- The Netherlands (NL)

- New Zealand (NZ)

- Sweden (SE)

- United Kingdom (UK)

- United States of America (USA)

The survey was created and distributed using the Jisc Online Surveys platform (https://www.onlinesurveys.ac,uk/, Jisc, Bristol, UK). An electronic link and covering email were sent to every radiotherapy department in each country by that country's local contact, with start dates ranging from June 2018 to March 2019. Reminder emails were sent every 24 weeks to maximise partícipation rate, with further encouragement given to nonresponding centres. The survey was closed in each country after a total of eight weeks or when a $100 \%$ response rate was reached.

Due to the wide range of MRI pulse sequences available and vendor-specific naming conventions, sequences were summarised by weighting and acquisition method, specifically 
as: T1-weighted ( $\mathrm{T} 1 \mathrm{w})$ or $\mathrm{T} 2$-weighted $(\mathrm{T} 2 \mathrm{w}), 2 \mathrm{D}$ or $3 \mathrm{D}$, and whether contrast agent/fluid/fat suppression was used.

The terminology for MRI scanners dedicated to RT treatment planning is ill-defined but they are often referred to as MRI simulators or MRI sims in the literature. MRI scanners for EBRT are not used in the same way that CT-simulators were once used in the RT field and hence within this manuscript, the term 'dedicated MRI for RT' is used. This term is defined here as an MRI scanner with such auxiliary equipment that patients can be scanned in the treatment position. For example, a flat-top couch and indexed immobilisation equipment.

Where reported, the medians (and ranges) between countries were generated by taking the median value (\%) across all country responses. Values per country (\%) were determined using the number of responding centres per question. This means percentage values quoted do not necessarily represent the \% of overall centres per country as some centres responded to the survey but did not fill in every question.

\section{Results:}

The response rate in the USA was $<1 \%$ (9 centres) and hence results can only be considered representative of these specific centres and not representative of the country. Due to this these results have been omitted from the analysis. In other countries, the survey had a median response rate of $77 \%$ per country (185/442 absolute total), response rates for individual countries are shown in Table 1. Response rates varied between those with: $100 \%$ response rate (Denmark/Finland), where results are entirely representative of the country, high response rates of $67-92 \%$ in Belgium/the Netherlands/New Zealand/Sweden/UK, and those with low response rates of $13-31 \%$ in Australia/France/Italy.

Country rate $(\%)$ (Absolute number)

$\begin{array}{ccc}\text { Finland } & 100 & 13 / 13 \\ \text { Denmark } & 100 & 8 / 8 \\ \text { Belgium } & 92 & 22 / 24\end{array}$




\begin{tabular}{ccc} 
The Netherlands & 90 & $17 / 19$ \\
UK & 87 & $62 / 71$ \\
New Zealand & 67 & $6 / 9$ \\
Sweden & 67 & $6 / 9$ \\
Australia & 31 & $11 / 36$ \\
Italy & 22 & $19 / 86$ \\
France & 13 & $21 / 167$ \\
\hline Overall & 77 & $185 / 442$
\end{tabular}

Table 1. Response rates in \% and absolute number for each country, ranked by \% response rate. Note that the overall response rate (\%) quoted is the median for all countries.

\section{Access to MRI}

All responding centres, apart from 3 centres in France, reported some form of access to MRI for the RT planning process. These responses included centres using MRI from a Picture Archiving and Communication System (PACS), potentially acquired in another institution, or some form of direct MRI access. Direct MRI access was defined as either having a dedicated MRI for RT or access to a radiology MRI scanner within the same hospital with dedicated sessions or on an ad hoc basis. Of the centres using images from PACS, only a median of $9 \%$ (range $0-40 \%$ per country) perform any form of QA on the images. The percentage of responding centres per country with direct MRI access is displayed in Table 2, with the breakdown of types of shown in Figure 1.

Country

Denmark

The Netherlands

New Zealand

Sweden

Belgium

Finland

Australia

UK

Italy
Direct MRI access (\%)

100

100

100

100

91

85

82

69

68 
France 43

Table 2. Percentage of responding centres per country with direct MRI access, defined as having a dedicated MRI for RT or access to a radiology MRI scanner with dedicated or ad-hoc sessions.
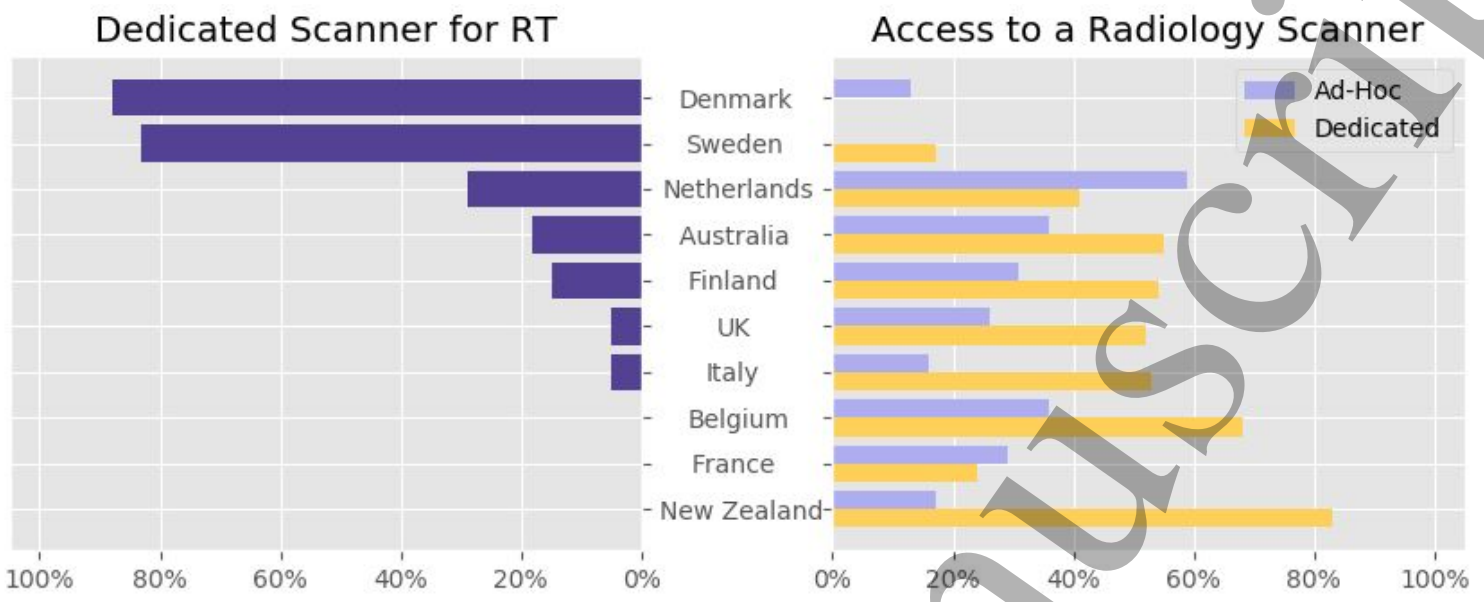

Figure 1. Percentage of responding centres per country with direct MRI access from either dedicated MRI for RT (left) or access to a radiology MRI scanner with dedicated or ad-hoc sessions (right). Note that centres could respond with multiple access types so the sum of all 3 access types can be over $100 \%$.

\section{Anatomical sites in which MRI is used for EBRT treatment planning}

There is large variation between countries in how MRI is being utilised for different anatomical sites. Table 3 shows the median and range of centres per country that have an MRI protocol for the seven most common anatomical sites. MRI is utilised most commonly in the brain, prostate, and head and neck anatomical sites, with all countries reporting that at least $50 \%$ of responding centres have an MRI protocol. The largest variation between countries was found for rectum and anus, with $0-77 \%$ (median: 53\%) of responding centres per country reporting to have an MRI protocol. Note, results in Table 3 do not indicate all patients of that anatomical site are scanned with MRI. To understand this further, centres were asked if the MRI protocol was used for all or some patients dependent on MRI availability or clinical need. Figure 2 shows results for the seven most common anatomical sites for each individual country. The brain is the site where MRI is routinely used for all patients in the greatest number of centres. 


\begin{tabular}{ccc} 
Anatomical site & Median (\%) & Range (\%) \\
\hline Brain & 88 & $75-100$ \\
Prostate & 83 & $60-100$ \\
Head and Neck & 74 & $50-92$ \\
Gynae & 64 & $30-76$ \\
Spine & 54 & $33-88$ \\
Rectum / Anus & 53 & $0-77$ \\
Liver & 33 & $17-78$ \\
\hline
\end{tabular}

Table 3. Median and range, from all countries, of responding centres within that country that have an MRI protocol for different anatomical sites. 
Brain

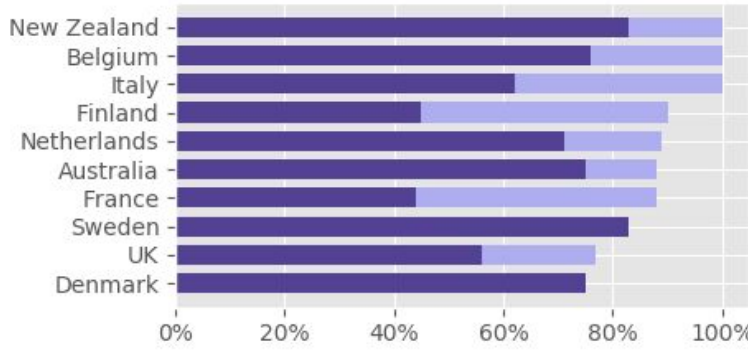

Head and Neck

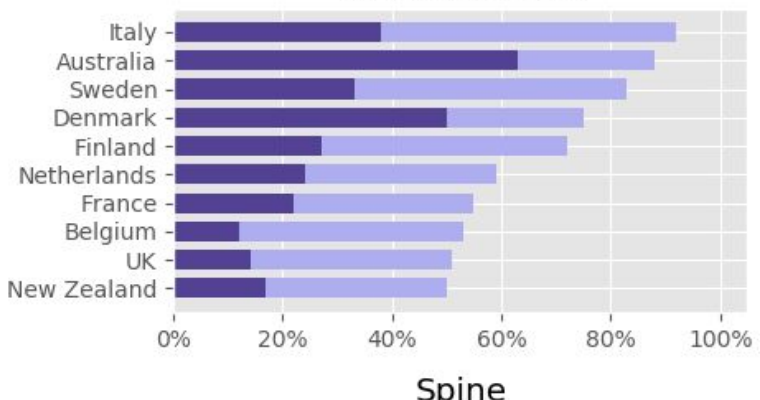

Spine

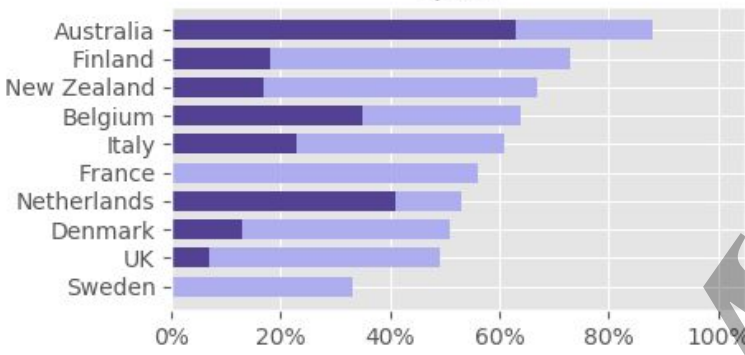

Liver

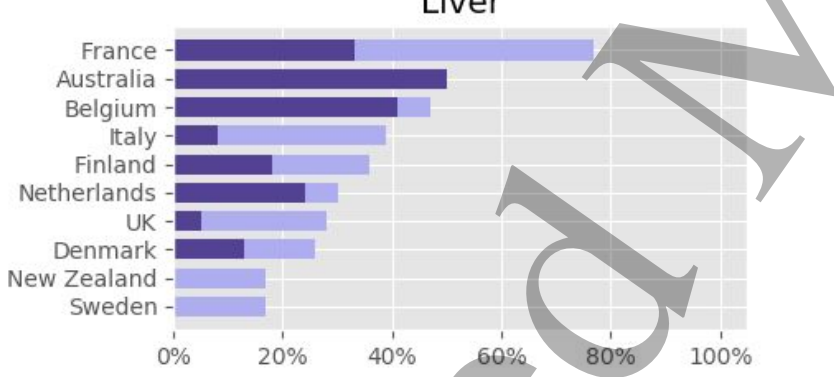

Key

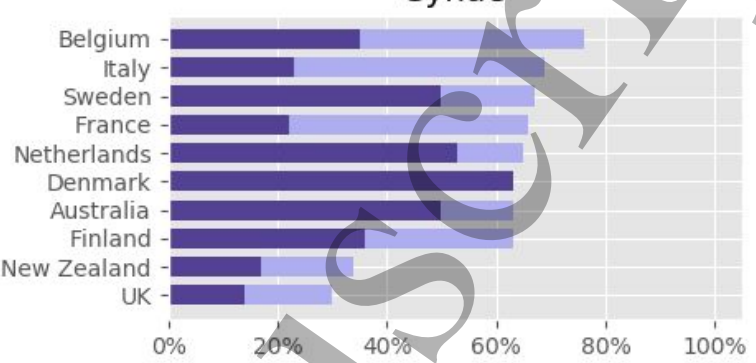

Rectum and Anus

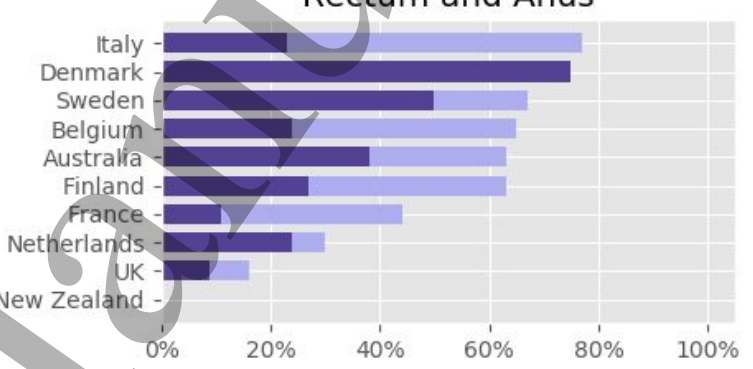

Figure 2. Percentage of responding centres per country that acquire $M R I$ either routinely for either all or some of their patients. Results are shown for the 7 most common anatomical sites.

\section{MRI equipment}

MRI scanner field strength of $1.5 \mathrm{~T}$ was the most commonly available, with access to 1.5 and $3 \mathrm{~T}$ shown in Figure 3 . Access to 0.35 or $1 \mathrm{~T}$ field strengths was reported in a very small number of centres (0-2 per country). The breakdown of dedicated RT laser access for MRI and its use for all, some or none of the MRI acquisitions per country is shown in Table 4. 
External RT laser access for MRI scanners was reported to be high ( $\geq 83 \%$ of centres) in Denmark and Sweden and low elsewhere ( $\leq 36 \%$ of centres).
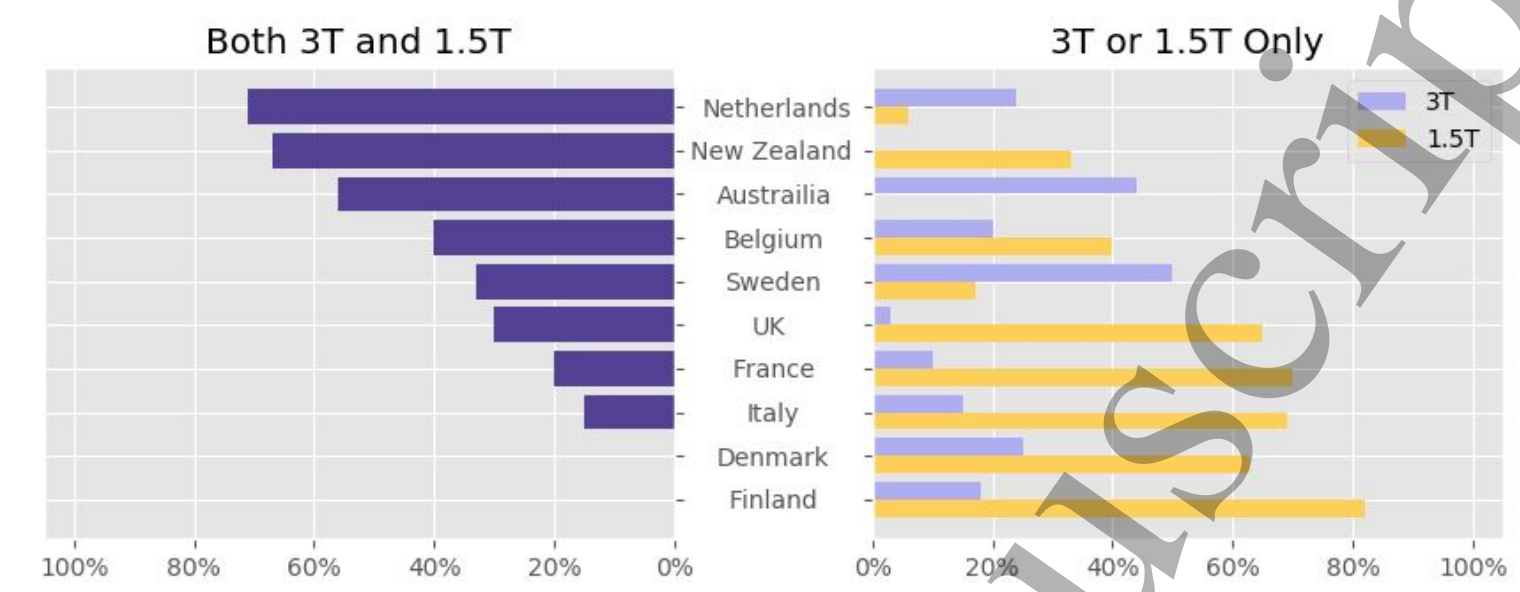

Figure 3. Percentages of responding centres per country with access to 1.5 and/or $3 T$ MRI scanners for RT planning purposes.

\begin{tabular}{cccc} 
& Lasers used for \\
all sites (\%) & $\begin{array}{c}\text { Lasers used for } \\
\text { Some sites (\%) }\end{array}$ & $\begin{array}{c}\text { No access } \\
\text { to lasers (\%) }\end{array}$ \\
\hline Denmark & 50 & 38 & 13 \\
Sweden & 33 & 50 & 17 \\
Finland & 18 & 18 & 64 \\
Australia & 11 & 11 & 78 \\
Netherlands & 6 & 18 & 76 \\
Belgium & 5 & 0 & 95 \\
UK & 5 & 10 & 86 \\
France & 0 & 0 & 100 \\
Italy & 0 & 0 & 100 \\
New Zealand & 0 & 0 & 100 \\
\hline
\end{tabular}

Table 4. Percentage of responding centres per country that use lasers to set up patients for all or some of their MRI acquisitions for RT as well as percentage of centres who do not have access to lasers to set up patients.

In order to acquire MRI in the treatment position a variety of specialist MRI equipment has been reported, see Table 5. Flat couch tops, knee blocks, coil bridges/supports and masks 
were the most commonly reported. While there was a large variation between countries, Sweden consistently reported having the most, or second most, access for every equipment type.

\begin{tabular}{ccc} 
Equipment type & Median (\%) & Range (\%) \\
\hline Flat couch top & 66 & $45-88$ \\
Knee blocks & 60 & $33-88$ \\
Coil bridges/supports & 51 & $17-83$ \\
Masks & 50 & $20-83$ \\
Ankle supports, foot stocks & 41 & $17-83$ \\
Vacuum bag & 35 & $10-83$ \\
Headboard & 33 & $15-73$ \\
Thorax, breast board & 20 & $0-38$ \\
None & 18 & $0-50$ \\
Abdominal compression & 13 & $0-30$ \\
Hand grips & 13 & $0-33$ \\
RT specific RF coils & 11 & $0-30$ \\
\hline
\end{tabular}

Table 5. Median and range, from all countries, of responding centres within that country who have access to various equipment types that can be used to immobilise patients on an MRI acquisition.

\section{MRI sequence details}

The MRI sequences used per anatomical site are detailed in Table 6 where all questions where a binary yes or no to having sequences avalable for RT purposes, not how often they are used. It is worth noting that this table reports results as a percentage of responding centres for this question and does not reflect the percentage of patients being scanned. For all anatomical sites it was reported that a combination of T1w, T2w, 2D and 3D sequences were acquired, with large amounts of variation within and between countries in sequence choice.

Contrast agent use was reported for all clinical sites but use varies both within and between countries. The brain was the only anatomical site where contrast agent is used by the majority of centres in every country and prostate is the anatomical site where contrast agent is used the least. Functional MRI (defined here as diffusion weighted imaging (DWI) and dynamic contrast enhanced (DCE) imaging) uptake is low in all countries, with brain and 
prostate being the most common anatomical sites (25\% (0-40\%) and $23 \%(0-40 \%)$ being the median and ranges for both respectively).

$\%$ of responding centres - median over all countries (range over all countries)

\begin{tabular}{cccccccc} 
& Head $\&$ & Brain & Spine & Liver & Prostate & Gynae & Rectum \\
& Neck & & & & & \\
Diagnostic & 43 & 56 & 39 & 22 & 50 & 31 & 29 \\
& $(0-80)$ & $(29-80)$ & $(15-50)$ & $(0-29)$ & $(11-88)$ & $(0-80)$ & $(0-88)$ \\
2D & 29 & 29 & 22 & 13 & 29 & 29 & 23 \\
& $(0-47)$ & $(11-60)$ & $(0-40)$ & $(0-29)$ & $(0-75)$ & $(0-63)$ & $(0-63)$ \\
3D & 33 & 60 & 22 & 20 & 29 & 22 & 14 \\
& $(0-60)$ & $(43-82)$ & $(0-50)$ & $(0-43)$ & $(8-50)$ & $(8-40)$ & $(0-38)$ \\
T1W & 57 & 83 & 50 & 23 & 41 & 35 & 29 \\
& $(11-85)$ & $(40-92)$ & $(0-62)$ & $(13-57)$ & $(33-77)$ & $(0-69)$ & $(0-69)$ \\
T2W & 50 & 61 & 47 & 18 & 71 & 60 & 29 \\
& $(0-70)$ & $(33-90)$ & $(0-67)$ & $(0-44)$ & $(44-80)$ & $(17-75)$ & $(11-75)$ \\
Fat & 40 & 20 & 25 & 17 & 24 & 13 & 11 \\
Suppression & $(0-63)$ & $(0-35)$ & $(0-40)$ & $(0-30)$ & $(0-50)$ & $(0-50)$ & $(0-40)$ \\
Gadolinium & 43 & 70 & 22 & 22 & 0 & 6 & 6 \\
Contrast & $(0-75)$ & $(56-82)$ & $(0-54)$ & $(0-43)$ & $(0-54)$ & $(0-46)$ & $(0-54)$ \\
Functional & 15 & 25 & 0 & 6 & 23 & 13 & 6 \\
& $(0-20)$ & $(0-40)$ & $(0-15)$ & $(0-14)$ & $(0-40)$ & $(0-30)$ & $(0-25)$ \\
\hline
\end{tabular}

Table 6. Details of MRI sequence used for a range of anatomical sites. Individual countries medians were taken from all responding centres to this question from that country. Results shown here are median (and range) of the individual countries median responses.

\section{MRI to CT registration}

The vast majority of centres utilise rigid MRI to CT registration, with only four responding centres reporting not using rigid registration for RT treatment planning. Of the centres not using rigid registration, three reported using deformable registration only (one in Belgium and two in (taly) and one Belgian centre reported not using any registration. The uptake of deformable registration for RT treatment planning varies between countries with $>38 \%$ of responding centres in Italy/Finland reporting using it, approximately $20 \%$ in the Netherlands/UK and $\leq 10 \%$ everywhere else. 
A variety of tests were identified for the commissioning of MRI to CT registration software, with the tests and median/range of centres per country which carry them out summarised in Table 7. Qualitative assessment of patient registrations (median 67\%) and checkerboard/overlap of patient or phantom registrations (median 37\%) were the most common responses, followed by quantitative assessment of phantom registrations (median $30 \%)$.

\begin{tabular}{ccc} 
Commissioning test & Median (\%) & Range (\%) \\
\hline Qualitative - Patient Registration & 67 & $20-100$ \\
Checkerboard, overlap on phantoms or patients & 37 & $10-69$ \\
Quantitative - physical phantom registrations & 30 & $0-75$ \\
End-to-end tests & 20 & $0-50$ \\
Quantitative - landmark alignment & 14 & $0-40$ \\
Quantitative - digital phantom registrations & 9 & $0-43$ \\
Quantitative - contours on registered images & 7 & $0-21$ \\
Deformation Map & 2 & $0-30$ \\
Jacobian Determinant & 0 & $0-13$ \\
Consistency, or transitivity & 0 & $0-13$ \\
\hline
\end{tabular}

Table 7. Median and range, from all countries of responding centres within that country, of centres carrying out different tests for commissioning of MR to CT registration software.

In every country, less than $20 \%$ of centres reported performing quantitative assessment of registrations on a per patient basis, with no centres in Australia, Belgium, Italy, and France reporting such tests. It was reported that 1-3 centres performed quantitative assessment for every patient in Denmark, Sweden, the Netherlands, and the UK, whilst 1-3 centres within Finland, New Zealand, and the UK performed quantitative assessment when qualitative assessment of patient registration fails.

\section{MRI commissioning and QA}


A large variation within and between countries in phantoms used for MRI commissioning and quality assurance (QA) was reported, with the ACR phantom (Newmatic Medical, Grand Rapids, Michigan, USA) and Quasar MRID 3D (Modus Medical Devices Inc, London ON, Canada) being the most common commercial phantoms, with a median (range) of $33 \%$ (0$100 \%$ ) and $12 \%(0-27 \%)$ respectively. In all countries, between $8 \%$ and $67 \%$ of centres produced their own in-house large field of view (FoV) geometric distortion phantoms.

The frequency of performing various MRI QA tests is shown in Table 8, and it can be seen that not performing QA was the most common response at all frequencies except commissioning. Many centres reported performing MRI commissioning tests, but there is a wide variation in what tests are being performed and even the most common test (image quality) was only performed in a median of $32 \%$ of centres in each country. Beyond commissioning there is very little QA performed and where it is done there is little consistency in what's done and at what frequency. The most common test reported beyond commissioning was image quality assessed on a weekly basis, which was performed by a median of $16 \%$ of centres per country.

\begin{tabular}{|c|c|c|c|c|c|}
\hline & 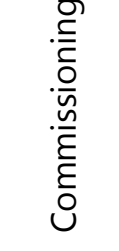 & & & 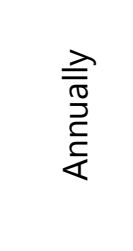 & 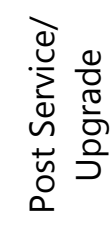 \\
\hline No QA & $\begin{array}{c}20 \\
(0-51)\end{array}$ & & & $\begin{array}{c}19 \\
(0-50)\end{array}$ & $\begin{array}{c}16 \\
(0-50)\end{array}$ \\
\hline Image Quality & & & & $\begin{array}{c}1 \\
(0-13)\end{array}$ & $\begin{array}{c}4 \\
(0-15)\end{array}$ \\
\hline $\begin{array}{c}\text { Laser } \\
\text { Positionin }\end{array}$ & $0-6$ & $\begin{array}{l}0 \\
0-25)\end{array}$ & $\begin{array}{c}3 \\
(0-23)\end{array}$ & $\begin{array}{c}0 \\
(0-10)\end{array}$ & $\begin{array}{c}0 \\
(0-40)\end{array}$ \\
\hline $\begin{array}{l}\text { Small FoV } \\
\text { distortion }\end{array}$ & $\begin{array}{c}30 \\
(0-50)\end{array}$ & $\begin{array}{c}1 \\
(0-60)\end{array}$ & $\begin{array}{c}9 \\
(0-30)\end{array}$ & $\begin{array}{c}6 \\
(0-25)\end{array}$ & $\begin{array}{c}0 \\
(0-23)\end{array}$ \\
\hline $\begin{array}{l}\text { Large FoV } \\
\text { distortion }\end{array}$ & $\begin{array}{c}25 \\
(0-80)\end{array}$ & $\begin{array}{l}0 \\
-23)\end{array}$ & $\begin{array}{c}13 \\
(0-40)\end{array}$ & $\begin{array}{c}9 \\
(0-25)\end{array}$ & $\begin{array}{c}0 \\
(0-20)\end{array}$ \\
\hline $\begin{array}{l}\text { Couch } \\
\text { Movement }\end{array}$ & $\begin{array}{c}13 \\
(0-40)\end{array}$ & $\begin{array}{c}0 \\
0-8)\end{array}$ & $\begin{array}{c}4 \\
(0-38)\end{array}$ & $\begin{array}{c}0 \\
(0-20)\end{array}$ & $\begin{array}{c}0 \\
(0-20)\end{array}$ \\
\hline
\end{tabular}


$\begin{array}{ccccccccc}\text { Couch Flatness } & 16 & 0 & 0 & 1 & 0 & 0 & 0 & 0 \\ & (0-40) & (0-0) & (0-8) & (0-13) & (0-0) & (0-13) & (0-25) & (0-15)\end{array}$

$\begin{array}{ccccccccc}4 \mathrm{D} \text { Tests } & 3 & 0 & 0 & 0 & 0 & 0 & 0 & 0 \\ & (0-20) & (0-0) & (0-0) & (0-13) & (0-10) & (0-0) & (0-10) & (0-0)\end{array}$

Table 8. Median (and range) of percentage of centres responding from within a country carrying out different MRI QA tests at various frequencies.

\section{MRI safety}

The majority of centres reported additional safety features and practices over and above those which would be in place for a diagnostic scanner (see Table 9) with additional training, policies and arrangements being the most common safety features. Less common but with a wide variety between countries were additional millitesla (mT) lines marked on the floor of the MRI suite (the mT line displayed varied, with 2, 3, 5, 10 and $20 \mathrm{mT}$ being reported by multiple centres and $200 \mathrm{mT}$ being reported by a single centre), as well as ferromagnetic detectors.

\begin{tabular}{ccc} 
Safety feature reported & Median (\%) & Range (\%) \\
\hline Training & 80 & $60-93$ \\
Policies and arrangements & 73 & $38-100$ \\
Additional $\mathrm{mT}$ line marked on floor & 38 & $0-100$ \\
Ferromagnetic detectors & 13 & $0-92$ \\
\hline
\end{tabular}

Table 9. Median and range, from all countries of responding centres within that country, of centres reporting different additional MRI safety features.

\section{Workflow, staffing and training}

The staff groups performing contouring on MRI scans are shown in Table 10. Oncologists are the most common staff group performing contouring in all countries. It was also reported that oncologists are supported by a wide variety of staff groups in contouring, and this varies a lot both within and between countries. 
The staff groups attending and setting up patients on MRI scanners are shown in Table 11. MRI radiographers are the most common staff group present during MRI scanning in all countries, except Denmark where it is RT radiographers instead. This trend continues for the staff group setting patients up on the MRI scanner, with MRI and RT radiographers being the first and second most common answer respectively. The training and education for MRI and RT radiographers is undertaken through a mix of local induction and formal programs of study, with details of training provided shown in Table 12 and Table 13 respectively.

\begin{tabular}{ccc}
$\begin{array}{c}\text { Staff groups performing } \\
\text { contouring }\end{array}$ & $\begin{array}{c}\text { Median } \\
(\%)\end{array}$ & $\begin{array}{c}\text { Range } \\
(\%)\end{array}$ \\
\hline Oncologist & 87 & $56-100$ \\
RT radiographer & 39 & $5-100$ \\
Radiologist & 32 & $0-88$ \\
RT physicist & 20 & $0-67$ \\
Dosimetrist & 11 & $0-40$ \\
Dual trained radiographer & 7 & $0-33$ \\
MR radiographer & 6 & $0-44$ \\
MR physicist & 6 & $0-56$ \\
\hline
\end{tabular}

Table 10. Median and range, from all countries of responding centres within that country, of the staff groups performing contouring on MRI, note centres could have multiple replies if necessary.

\begin{tabular}{ccc} 
Staff group & $\begin{array}{c}\text { \% present during } \\
\text { MRI scans }\end{array}$ & $\begin{array}{c}\text { \% setting up patients } \\
\text { during MRI scans }\end{array}$ \\
\hline MR radiographer & $86(38-100)$ & $68(38-83)$ \\
RT radiographer & $50(11-78)$ & $50(8-78)$ \\
Dual trained radiographer & $13(0-38)$ & $17(0-38)$ \\
RT physicist & $6(0-17)$ & $0(0-17)$ \\
Radiologist & $2(0-75)$ & $0(0-33)$ \\
MR physicist & $0(0-11)$ & $0(0-0)$ \\
Oncologist & $0(0-31)$ & $0(0-15)$ \\
Assistant practitioner & $0(0-8)$ & $0(0-3)$ \\
\hline
\end{tabular}

Table 11. Median (and range), from all countries of responding centres within that country, of the staff groups present and setting up patients during MRI scans, note centres could have multiple replies if necessary. 


\begin{tabular}{ccc}
$\begin{array}{c}\text { Type of RT specific Training/ Education } \\
\text { for MRI radiographers }\end{array}$ & $\begin{array}{c}\text { Median } \\
(\%)\end{array}$ & Range (\%) \\
\hline Imaging needs for RT planning & 76 & $33-100$ \\
Observation of CT simulation & 35 & $15-50$ \\
Use of single imaging isocentres & 16 & $0-56$ \\
None & 16 & $0-38$ \\
Use of RT lasers & 14 & $0-33$ \\
\hline
\end{tabular}

Table 12. Median and range, from all countries of responding centres within that country, of RTspecific training and education provided for MR Radiographers working on a dedicated MRI scanner for RT, note centres could have multiple replies if necessary.

\begin{tabular}{ccc}
$\begin{array}{c}\text { Type of MRI specific Training/ } \\
\text { Education for RT radiographers }\end{array}$ & $\begin{array}{c}\text { Median } \\
(\%)\end{array}$ & Range (\%) \\
\hline MRI safety & 70 & $57-100$ \\
MRI theory & 57 & $0-69$ \\
In-house tutorials & 55 & $10-100$ \\
Shadowing in MRI & 38 & $10-71$ \\
MRI screening & 33 & $8-69$ \\
Local workbook activities & 18 & $0-43$ \\
Other MRI courses & 17 & $0-43$ \\
Study days & 13 & $0-43$ \\
Postgrad MRI modules & 5 & $0-31$ \\
\hline
\end{tabular}

Table 13. Median and range, from all countries of responding centres within that country, of MRIspecific training and education provided for RT Radiographers working on a dedicated MRI scanner for RT, note centres could have multiple replies if necessary.

The MRI physics support available to centres is predominantly from RT physicists with MRI knowledge (see Table 14), with this being the most common answer in Denmark, Finland Italy, the Netherlands, and France. Other countries most common responses were: RT dedicated MRI physicists (Sweden), Non-RT dedicated MRI physicist (UK), and no MRI physics support (Australia, Belgium and New Zealand).

\begin{tabular}{ccc} 
Type of MRI physics support & Median (\%) & Range (\%) \\
\hline RT physicist with MR knowledge & 39 & $14-76$ \\
Non-RT dedicated: MR physicist & 23 & $11-50$ \\
RT dedicated: MR physicist & 21 & $0-67$
\end{tabular}


None

MR physicist from another institution

3

$0-11$

Table 14. Median and range, from all countries of responding centres within that country, of type of physics support available to centres when setting up a new MRI service.

\section{Barriers to implementation of MRI for EBRT planning}

The greatest reported challenge of incorporating MRI in the EBRT pathway was the lack of access to MRI (see Table 15), this was true for every country except Sweden and Denmark, where no financial reimbursement for MRI scans and clinical interest were the greatest reported challenges respectively. Behind a lack of MRI access, no financial reimbursement for MRI scans is a key barrier with all countries reporting that to be the first or second most common barrier to increased amounts of MRI for RT.

\begin{tabular}{lcc}
\multicolumn{1}{c}{ Barriers for using more MRI in RT } & Median (\%) & Range (\%) \\
\hline MRI access & 75 & $13-100$ \\
No financial reimbursement for MR scans & 44 & $33-64$ \\
Lack of knowledge, and/or support locally & 17 & $0-26$ \\
Lack of clinical interest & 14 & $0-50$ \\
None & 0 & $0-13$ \\
\hline
\end{tabular}

Table 15. Median and range, from all countries of responding centres within that country, of the barriers preventing more MRI for RT, note centres could have multiple replies if necessary.

\section{Future applications of MRI}

It was reported that functional MRI is currently being used in some capacity at a median of $33 \%$ of centres in each country. The current and anticipated introduction over the next 5 years of functional MRI is shown for each country in Figure 4. In free text comments boxes common themes in responses where that there is a lack of evidence on how to implement functional MRI as well as concerns regarding the geometric fidelity of such sequences. It was reported that there is a lot of interest in increasing the role of functional MRI, in particular in Denmark and the Netherlands where over half of centres are planning to do this within the next 5 years. 
Although in all countries over $50 \%$ of centres are not planning for a new MRI scanner, there is a lot of interest in increasing the amount of MRI scanners dedicated to RT within the next 5 years (see Figure 5), with at least $10 \%$ of centres in every country reporting plans for a new MRI scanner for RT either as a new scanner or replacement for a current scanner. In terms of absolute numbers this equates to 52 new MRI scanners, with the UK reporting to have the largest absolute increase, with 23 of these.

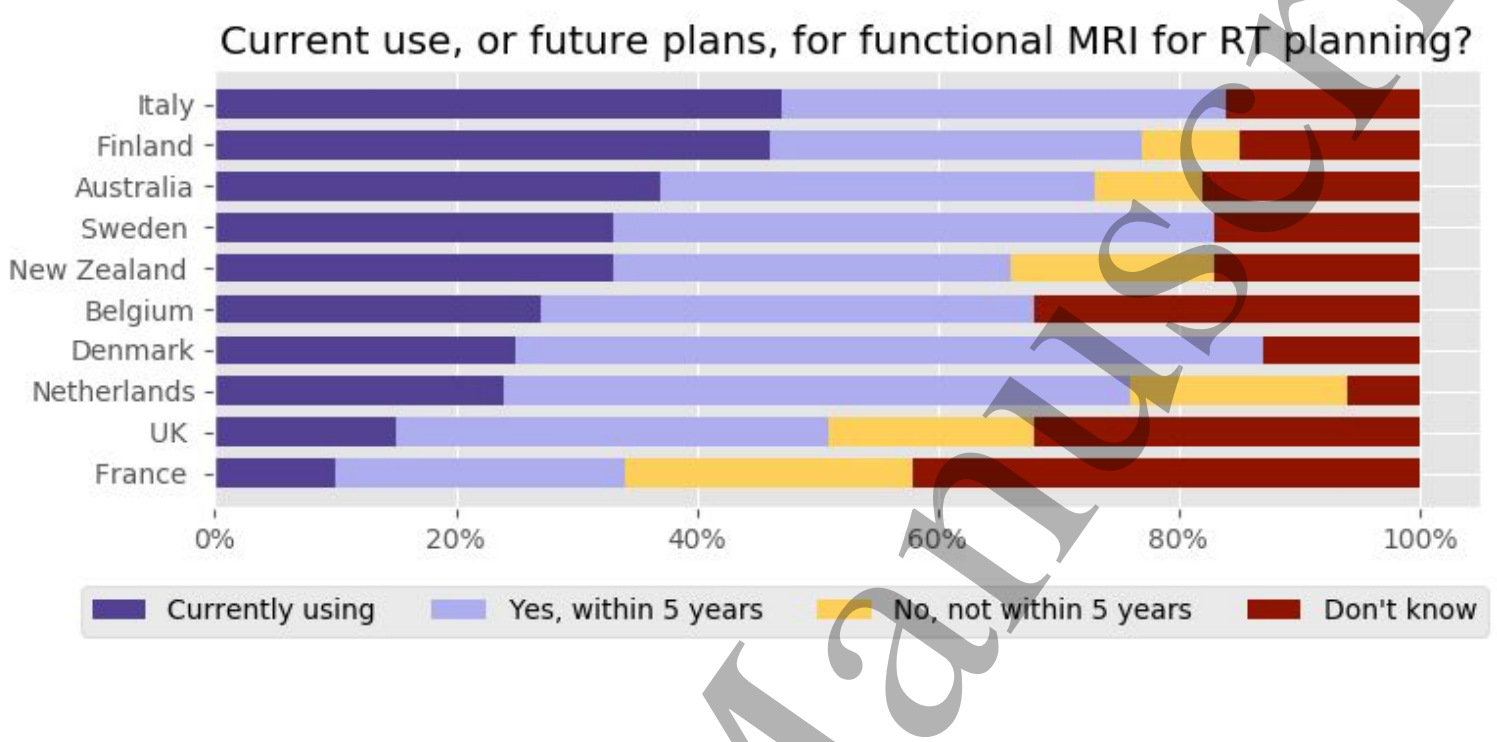

Figure 4. Current use and future plans for the role of functional MRI for EBRT in each country, all results shown are percentages of responding centres for this question in that country.

MR-only radiotherapy was reported to be used clinically by small numbers of centres in all countries except Denmark, the UK and New Zealand (see Figure 6). However, there is a lot of interest in using it within 5 years, with a median of $50 \%$ of centres per country (range 11$89 \%)$ planning to use it and the largest interest in terms of absolute numbers being in the UK (10) and the Netherlands (8).

MRI linac technology was reported to be in clinical use by a small number of centres in Australia, Denmark, the Netherlands and the UK (see Figure 7). However, there is some interest in using it with a median of $14 \%$ of centres per country (range 0-35\%) planning to use it within the next 5 years. It is expected to be most prevalent in the Netherlands (10), the UK (8) and Denmark (5), with little interest (0 or 1 centres) reported in having or planning to have a MRI linac within 5 years in Sweden, Italy and Finland. 


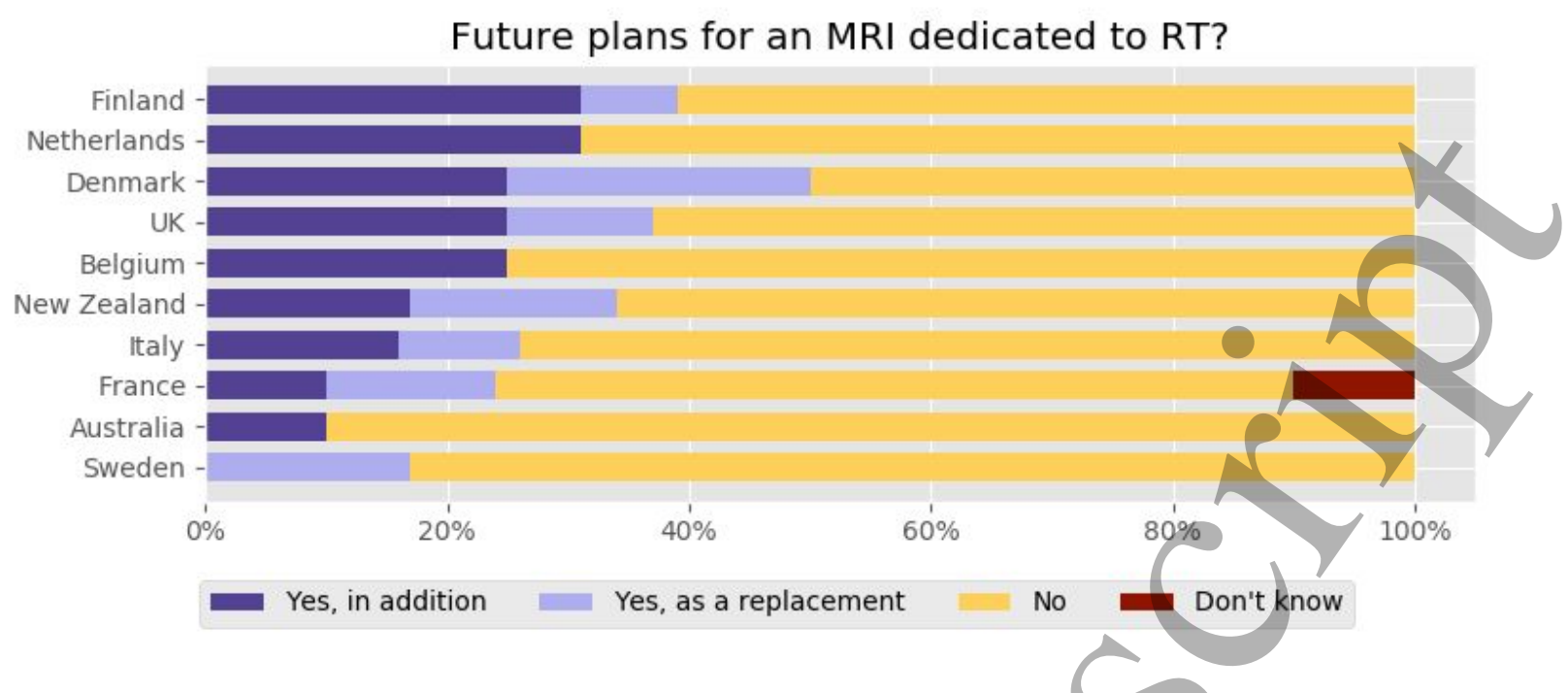

Figure 5. Future plans for a MRI scanner dedicated to RT in each country, all results shown are percentages of responding centres for this question in that country.

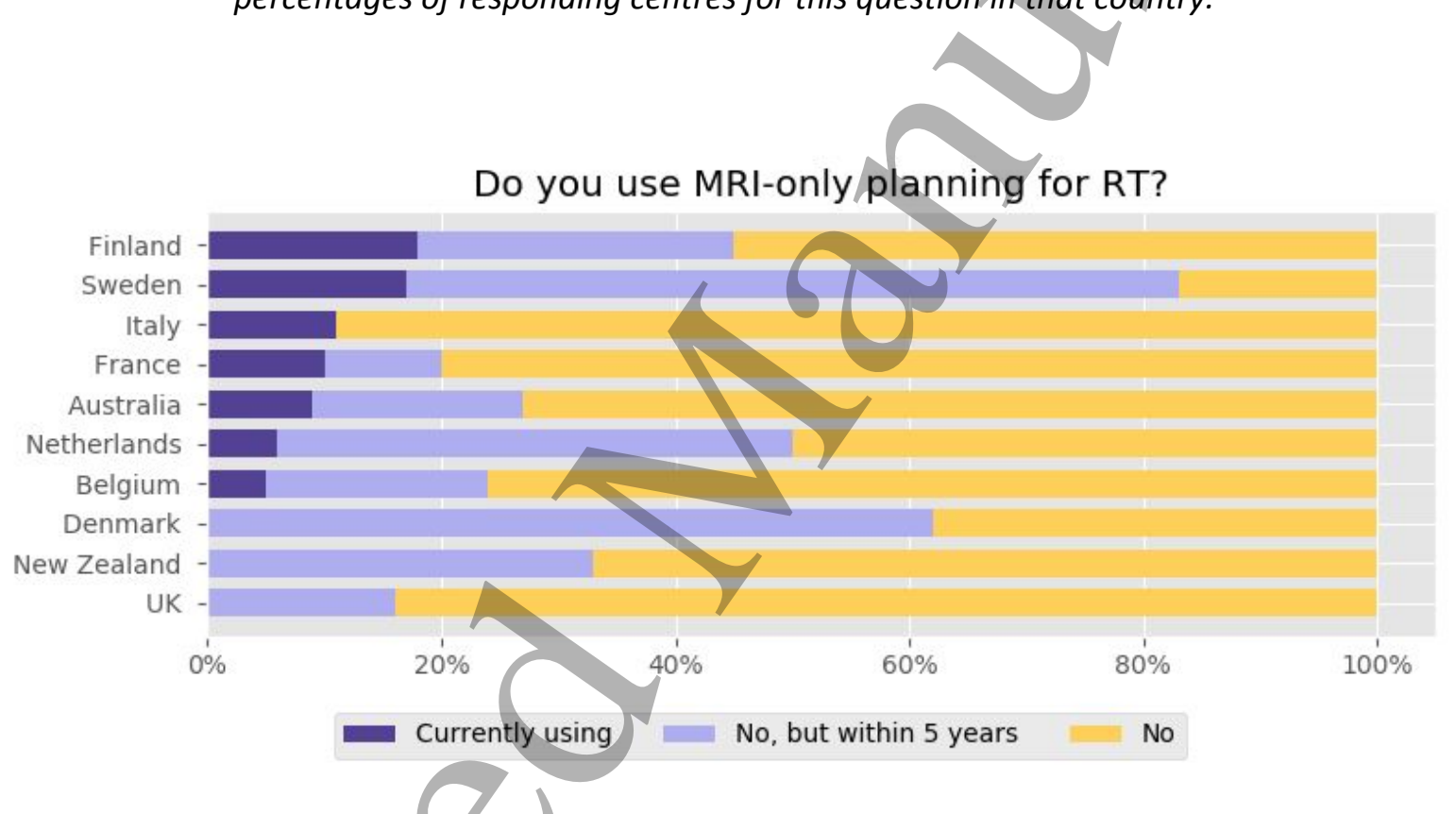

Figure 6. Current use and future plans for the role of MRI-only RT planning in each country, all results shown are percentages of responding centres for this question in that country. 


\section{Discussion}

Figure 7. Current use and future plans for the role of MRI-linac technology in each country, all results shown are percentages of responding centres for this question in that country.

It is important to note that the results, and conclusions drawn from these results, are only relevant for the countries involved in the survey. Countries were included that had a suitable local contact who was well respected in the field of MRI in EBRT within that country and who had the time to commit to this work. The authors believe that having a local contact was vital to ensure the questions/language were suitable as well as to increase response rate. Local contacts were approached who were known to the authors, and unfortunately there were a number of countries where potential local contacts were approached who did not accept the invitation to participate. This and the poor response rate in the USA, means that results are limited to Europe Australia and New Zealand and no results on MRI for EBRT can be inferred from North America, South America, Asia or Africa.

Before this work it was expected that uptake of MRI for EBRT would vary between countries in part due to the variations in the method and level of healthcare funding in different parts of the world. EBRT funding differences between countries are not fully understood but it is known that, for example, across the European Union the healthcare costs for cancer care vary substantially between an average of 33 Euro per person per year adjusted using the purchasing power parity method in Lithuania and 171 Euro in Germany (Luengo-Fernandez et al 2013). Furthermore, if the healthcare costs per capita are considered as a surrogate for 
RT healthcare costs, which may not be a good indicator but access to RT data is not available, then Table 16 shows that there is significant variation between the countries surveyed both in terms of \% of GDP (8.7-17.0) and absolute costs per capita (3649.211071.7 USD). This variation in healthcare costs, or the size of RT centre also shown in Table 16 , do not correlate to any the variations reported in this study and the main stand out message from Table 16 is that the USA healthcare spending is higher than all other countries surveyed here.

The mean number of EBRT treatment machines per centre (Table 16), which is a surrogate for the mean size of centres, along with the absolute number of centres contacted in each country (Table 1 ) indicates that countries with a large number of smaller centres were least likely to respond to the survey. It is hypothesized this is partly due to smaller centres having less staff available to respond as well as being less likely to have MR for RT access so may have less motivation to respond. Furthermore in countries with small numbers of centres is more likely that the local contact is known personally, which is expected to increase response rate. Therefore the poor response rate in the USA could, in part, be explained by its large number of small RT centres compared to all other countries involved. The main exception to this hypothesis is the UK with a high number of centres, however it is well represented in the authorship which increases the likelihood that one of the authors is known personally to a given centre as well as the request for filling in the survey in the UK coming affiliated with a professional body, (IPEM).

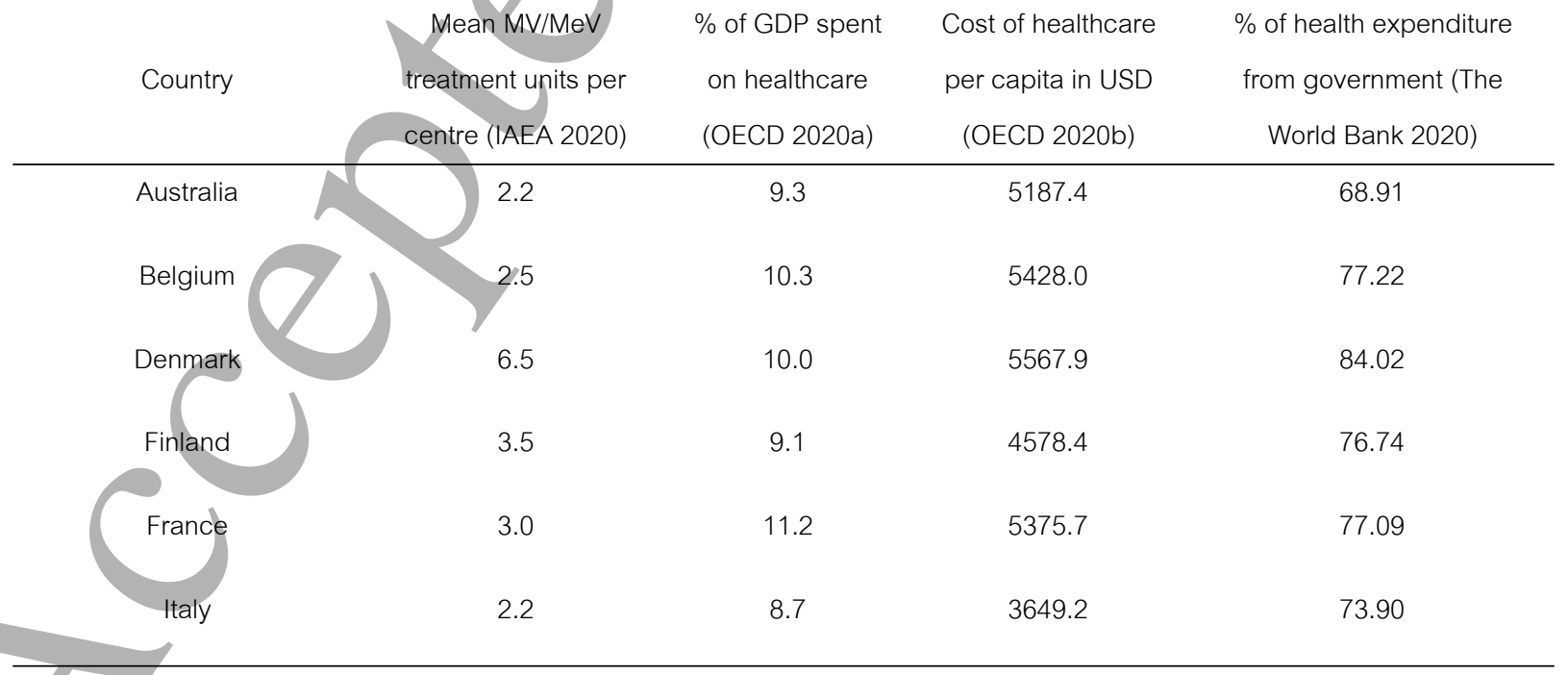


Table 16. Details of centre size and economic factors for all counties surveyed. Average number of $\mathrm{MV} / \mathrm{MeV}$ treatment units per centre is used as a surrogate for the size of RT centre. \% of GDP spent on healthcare data and cost of healthcare per capita in USD cover funding from all finance schemes and are included as a surrogate for RT healthcare costs as this data is not available for every country.

An evidence base for the benefits of a new, complex and rapidly evolving technology such as MR for EBRT is preferable in order for it to be adopted. However, there have been previous examples of new technology being widely adopted as the evidence is being established (such as the implementation of intensity modulated radiotherapy). Any such evidence base must be fed into a cost benefit analysis for any funders or local healthcare providers to decide if the new technique is feasible and deliverable. Therefore, even when the evidence base is strong for a new technique, the financial implications of implementing the new technique will vary depending on the overall healthcare budgets, which vary significantly, as shown in Table 16. The literature has started to demonstrate an evidence base for RT planning but more work is required. For example it has been demonstrated that MR in the EBRT planning pathway can reduce toxicity rates for both standard fractionation and hypofractionated prostate treatments (Sander et al 2014, Wortel et al 2017). Furthermore, it is hypothesized that MRI in the EBRT pathway can facilitate more accurate integrated boost regimes that could allow for better cure rates. This has recently been assessed for prostate treatments with standard fractionation in the FLAME phase 3 trial which demonstrated no increase in toxicity after 2 years follow up (Monninkhof et al 2018), and with hypofractionation, in the primary endpoints analysis of the hypo-FLAME phase 2 trial which demonstrated acceptable acute toxicity including no grade $\geq 3$ toxicity (Draulans et al 2020). 
MRI access was reported to be high, with all but 3 responding centres having at least some limited access to MR for EBRT planning. However, when it comes to direct MRI access (a dedicated MR for RT scanner or direct access to a scanner owned by radiology) half of the countries surveyed had $\geq 15 \%$ of centres without direct MR access. Only Sweden and Denmark have appreciable amounts of dedicated MR for EBRT provision ( $\geq 83 \%$ ), with the next closest being the Netherlands (29\%) and 5 countries surveyed having poor $(<10 \%)$ dedicated MR for EBRT access. It is thought this variation in dedicated MR for RT provision is a direct consequence of Denmark and Sweden being the only countries where prior national initiatives have specifically funded an increase in MR for EBRT provision. For other countries with a lower percentage of centres with dedicated MRI for RT, the reliance on MRI access on a radiology scanner increases and hence collaboration between RT and Radiology becomes more important.

A large variation both within and between countries was reported for the amount of uptake of MR for EBRT per anatomical site. The results here suggest that this is due to a combination of factors such as lack of an evidence base for the need for MRI, lack of guidance or consensus in the literature and clinical interest locally. At an international level there is significant variation, for example: the UK has comparatively low percentages of centres performing MRI for all anatomies; and New Zealand has a comparatively high percentage of centres performing MRI for brain and prostate anatomies, whereas it has a comparatively low percentage of centres performing MRI for head and neck, gynae, rectum and anus and liver anatomies. This significant variation in MR for EBRT use between countries, as well as significant percentage of centres not using MR for EBRT, even extends to the most common anatomies such as: brain, where there is a preference for using MRI from diagnostic pathway and many target and organ at risk volumes are poorly defined on $\mathrm{CT}$; and for prostate, despite the evidence in the literature that MR guidance can reduce toxicity (Wortel et al 2017, Sander et al 2014).

This survey has demonstrated a number of aspects of MR for EBRT use that have a large variation in practice both within and between countries. It is hypothesized that the variation in practice is in part due to the local knowledge at each centre as well as the lack of guidance and consensus in the literature. Availability of guidance or consensus would aid in harmonising how MR for EBRT was implemented as well as potentially helping MR in EBRT 
being more widely adopted. Some of the aspects that vary, such as equipment required, MR sequence optimisation, commissioning and $\mathrm{QA}$, and safety features could benefit from guidance from professional bodies. It is known that IPEM has published guidance (Speight et al 2021) and AAPM are working on such guidance, as well as the Nederlandse Commissie voor Stralingsdosimetrie (NCS) who are producing guidelines specifically on MRI QA for RT. Guidance is available for commissioning and QA of MRI scanners for diagnostic purposes (McRobbie and Semple 2017, ACR 2017, Jackson et al 2010), but the requirements for MR for EBRT are different from radiology and hence the QA requirements are different. Paulson et al. have proposed a QA programme for a dedicated MR scanner for RT (Paulson et al 2015) which is a good start for centres to follow, though the field would still benefit from guidance from professional bodies. Furthermore, this survey has demonstrated that the majority of centres are accessing MR for EBRT on a radiology MRI scanner. Such access will have time limitations which need to be considered when designing a QA programme. Some aspects of MR for RT use would be more consistent if current guidance was followed. For example the AAPM TG132 guidance (Brock, et al 2017) for image registration, which this survey shows many centres are not complying with. Finally, some aspects of practice would be more consistent if guidance was brought in at a national level and to some extent a staff discipline level, specifically aimed at the typical staff mix and baseline training in that country. Workflow, staffing and training are aspects that would benefit from national and discipline guidance, with an example being educational requirements guidance for therapeutic radiographers in the UK (SCOR 2020).

The lack of financial reimbursement for MR was a consistent barrier for all countries and MR access was a reported barrier for all countries except Sweden and Denmark. As previously discussed Sweden and Denmark had national initiatives to increase MR for RT provision, so it is understandable that MR access is less of an issue in these countries, although it is interesting to note that the on-going costs are still a limitation.

This survey has demonstrated that there is genuine interest in increasing the role of $M R$ within the next 5 years in the EBRT community. This comes despite the high investment required, both financial (capital and on-going costs) and effort (change to workflows and training all staff groups). The greatest interest is in the role of functional MR in guiding EBRT treatments and hence guidance or consensus in this field would be beneficial. The FLAME 
phase 3 clinical trial is a good example of how multiparametric MR can potentially lead to patient benefit (Monninkhof et al 2018). There is interest from the community for MR-only RT and for new MR scanners dedicated to RT, with 52 expected within 5 years across all countries surveyed. Therefore guidance on how to safely implement MR-only RT, as well as new dedicated MR scanners for RT, would be useful for the community. However, it is important that such guidance doesn't exclude centres that are not planning for new MR scanners, as these make up over $50 \%$ of centres in all countries. These centres would benefit from guidance on getting the best out of their current provision safely. To a lesser extent there is interest in on-line MR guided RT, with more specialist centres intending to purchase MR-linacs. It is hypothesised that the interest in the MR-linac is lower due to the high cost of this technology.

This work has identified differences in practice of the use of MR for RT. However, due to the granular nature of other aspects of radiotherapy in different countries, it was beyond the scope of this work to assess if the use of MR to guide treatment planning correlates to RT outcomes. This is in part due to the following factors that where not assessed: variations between academic and community hospitals; prevalence of different treatment fractionation (e.g., hypo-fractionation or conventional fractionation); prevalence of different treatment type (e.g., 3D conventional planning, intensity modulated RT or volumetric arc therapy); underlying health and lifestyle choices in each country.

The IPEM working party has addressed some of the issues identified in this work in the form of guidelines for the safe implementation for MR for EBRT (Speight et al 2021).

\section{Conclusion}

The MR in EBRT landscape has been comprehensively surveyed in 11 countries in order to assess the similarities and variations in practice. It was found that no single country has a comprehensive approach to MR for EBRT implementation and that there are financial barriers to increasing provision worldwide. Access to dedicated MR for RT scanners is limited in all but Sweden and Denmark, even here where national initiatives have funded capital costs there are still financial challenges with ongoing per-patient costs. There is a large variation in uptake of MR for different anatomical sites and, despite growing evidence 
that MR guidance can reduce toxicity, this is also true for prostate patients. Many aspects of $M R$ in EBRT practice vary widely, in part due to the lack of consensus in the literature or explicit guidance from professional bodies. The following have been identified as knowledge gaps: (1) staffing models/training, (2) QA of both MRI scanners and image registration and (3) sequences and the complimentary use of anatomical and functional information. Despite the challenges discussed there remains a high level of interest in increasing the role of $M R$ within the next 5 years in the EBRT community. It is the intention of the IPEM working party to fill the identified knowledge gaps by producing guidance to help centres safely implement MR for EBRT on a dedicated MR for RT scanner as well as getting the most out of limited access on current MRI scanners.

\section{Acknowledgment}

The authors would like to thank IPEM for supporting the working party and endorsing this survey. We would also like to thank all respondents to the survey - without the hard work from these centres the survey would not have been possible. Neelam Tyagi is thanked for coordinating the survey in the USA.

Dr Richard Speight is supported by the Sir John Fisher Foundation and Cancer Research UK Centres Network Accelerator Award Grant (A21993) to the ART-NET consortium. Dr Ben George is partly supported by a Cancer Research UK Centres Network Accelerator Award Grant (A21993) to the ART-NET consortium. Dr Cynthia Eccles is supported by the NIHR Manchester Biomedical Research Centre. Mr Michael Dubec is supported by CRUK via the funding to Cancer Research UK Manchester Centre: [C147/A18083] and [C147/A25254]. Mr Marcus Tyyger is supported by the Sir John Fisher Foundation.

\section{References}

ACR 2017 American College of Radiology MR Accreditation Program. Testing Instructions

Brock K K, Mutic S, McNutt T R, Li H and Kessler M L 2017 Use of image registration and fusion 
algorithms and techniques in radiotherapy: Report of the AAPM Radiation Therapy Committee Task Group No. 132 Med. Phys. 44 e43-76 Online:

https://aapm.onlinelibrary.wiley.com/doi/abs/10.1002/mp.12256

Cancer Research UK 2015 Achieving World Class cancer outcomes: Stratergy 2015 - 2020

Curran W J, Hackney D B, Blitzer P H and Bilaniuk L 1986 The value of magnetic resonance imaging in treatment planning of nasopharyngeal carcinoma Int. J. Radiat. Oncol. 12 2189-96 Online: http://www.sciencedirect.com/science/article/pii/0360301686900192

Draulans C, van der Heide U A, Haustermans K, Pos F J, van der Voort van Zyp J, De Boer H, Groen V H, Monninkhof E M, Smeenk R J, Kunze-Busch M, De Roover R, Depuydt T, Isebaert S and Kerkmeijer L G W 2020 Primary endpoint analysis of the multicentre phase II hypo-FLAME trial for intermediate and high risk prostate cancer Radiother. Oncol. $14792-8$

Erler D, D'Alimonte L and Campbell M 2018 Opportunity Is Knocking: The Need to Responsively and Responsibly Integrate Therapeutic MRI into Radiation Therapy J. Med. Imaging Radiat. Sci. 49 16-7 Online: https://doi.org/10.1016/j.jmir.2017.12.006

Glide-hurst C K, Low D A, Orton C G, Glide-hurst CK and Ph D 2016 MRI / CT is the future of radiotherapy treatment planning POINT / COUNTERPOINT MRI / CT is the future of radiotherapy treatment planning 110601 Online: http://dx.doi.org/10.1118/1.4894495

IAEA 2020 Directory of Radiotherapy Centres (DIRAC) Online: https://dirac.iaea.org/

Jackson E, Bronskill M, Drost D, Och J, Pooley R, Sobol W and Clarke G 2010 AAPM report 100 Acceptance Testing and Quality Assurance Procedures for Magnetic Resonance Imaging Facilities

Kupelian P and Sonke J-J 2014 Magnetic Resonance-Guided Adaptive Radiotherapy: A Solution to the Future Semin. Radiat. Oncol. 24 227-32 Online:

https://www.sciencedirect.com/science/article/pii/S1053429614000307

Liney G P 2018 Personal correspondence between G Liney and clinical staff at the Liverpool Cancer Therapy Centre Radiation Oncology Unit (Sydney Australia)

Luengo-Fernandez R, Leal J, Gray A and Sullivan R 2013 Economic burden of cancer across the European Union: A population-based cost analysis Lancet Oncol. 14 1165-74 Online: http://dx.doi.org/10.1016/S1470-2045(13)70442-X 
McRobbie D and Semple S 2017 Quality Control and Artefacts in Magnetic Resonance Imaging IPEM Report 112

Monninkhof E M, van Loon J W L, van Vulpen M, Kerkmeijer L G W, Pos F J, Haustermans K, van den Bergh L, Isebaert S, McColl G M, Smeenk R J, Noteboom J, Walraven I, Peeters P H M and van der Heide U A 2018 Standard whole prostate gland radiotherapy with and without lesion boost in prostate cancer: Toxicity in the FLAME randomized controlled trial Radiother. Oncol. 12774 80 Online: https://doi.org/10.1016/j.radonc.2017.12.022

OECD 2020a Organisation for economic co-operation and development Online: https://stats.oecd.org/

OECD 2020b Organisation for economic co-operation and development

Paulson E S, Erickson B, Schultz C and Allen Li X 2015 Comprehensive MRI simulation methodology using a dedicated MRI scanner in radiation oncology for external beam radiation treatment planning Med. Phys. 42 28-39 Online: https://aapm.onlinelibrary.wiley.com/doi/abs/10.1118/1.4896096

Pollard J M, Wen Z, Sadagopan R, Wang J and Ibbott G S 2017 The future of image-guided radiotherapy will be MR guided Br. J. Radiol. 9020160667 Online: http://www.birpublications.org/doi/10.1259/bjr.20160667

Raaymakers B W, Lagendijk J J W, Overweg J, Kok J G M, Raaijmakers A J E, Kerkhof E M, van der Put R W, Meijsing I, Crijns S P M, Benedosso F, van Vulpen M, de Graaff C H W, Allen J and Brown K J 2009 Integrating a 1.5 T MRI scanner with a 6 MV accelerator: proof of concept Phys. Med. Biol. 54 N229-37 Online: http://stacks.iop.org/00319155/54/i=12/a=N01?key=crossref.54089f06f82576151c8b56c369d3f175

Rai R, Kumar S, Batumalai V, Elwadia D, Ohanessian L, Juresic E, Cassapi L, Vinod S K, Holloway L, Keall P J and Liney G P 2017 The integration of MRI in radiation therapy: collaboration of radiographers and radiation therapists J. Med. Radiat. Sci. 64 61-8

Sander L, Langkilde N C, Holmberg M and Carl J 2014 MRI target delineation may reduce long-term toxicity after prostate radiotherapy Acta Oncol. (Madr). 53 809-14

SCoR 2020 MRI Guided Radiotherapy (London) Online: ISBN 978-1-909802-48-3

Speight R, Dubec M, Eccles C L, George B, Henry A, Herbert T, Johnstone R I, Liney G P, McCallum H M and Schmidt M A 2021 IPEM topical report: guidance on the use of MRI for external beam 
radiotherapy treatment planning Phys. Med. Biol. Online: https://doi.org/10.1088/1361$6560 / a b d c 30$

Speight R, Schmidt M A, Liney G P, Johnstone R, Eccles C, George B, Henry A and McCallum H M 2019 IPEM Topical Report: A 2018 IPEM survey of MRI use for external beam radiotherapy treatment planning in the UK Phys. Med. Biol. 64175021 Online: iopscience.iop.org/article/10.1088/1361$6560 / a b 2 c 7 c$

The World Bank 2020 Domestic general government health expenditure (\% of current health expenditure) Online:

https://data.worldbank.org/indicator/SH.XPD.GHED.CH.ZS?end=2017\&start=2017\&view=map

Wortel R C, Heemsbergen W D, Smeenk R J, Witte M G, Krol S D G, Pos F J and Incrocci L 2017 Local Protocol Variations for Image Guided Radiation Therapy in the Multicenter Dutch Hypofractionation (HYPRO) Trial: Impact of Rectal Balloon and MRI Delineation on Anorectal Dose and Gastrointestinal Toxicity Levels Int. J. Radiat. Oncol. Biol. Phys. 99 1243-52 Online: https://doi.org/10.1016/j.ijrobp.2017.07.044

Zubizarreta E, Van Dyk J and Lievens Y 2017 Analysis of Global Radiotherapy Needs and Costs by Geographic Region and Income Level Clin. Oncol. 29 84-92 Online:

http://dx.doi.org/10.1016/j.clon.2016.11.011 